\title{
A small world experiment in the digital era: Can sWOM be used by start uppers to reach a target?*
}

\author{
Francesca Pucciarelli ${ }^{* *}$, Chiara Giachino* ${ }^{* *}$, Bernardo Bertoldi ${ }^{* *}$, \\ Davide Tamagno*
}

\begin{abstract}
The rapid growth of Web 2.0 coupled with its unique capabilities has increasingly captured the attention of scholars and practitioners, and the list of benefits for companies of any age, size, and geography is continuously accrued by new evidences.

This paper contributes to the literature in the field by investigating the potential impact of social media, and especially of social Word-of-Mouth (sWOM), in boosting start-ups growth. This study applies an original approach on the topic, by replicating the Small World Experiment of Milgram. An empirical experiment of information diffusion process in the ESCP Europe community - chosen as example of a determined and closed social network, composed by a lot of start uppers - enabled authors to demonstrate that interconnected communities can enhance the WOM effect and consequently can represent an effective tool to help people looking for opportunities, such as start uppers, to reach a specific target; in the dissemination process if super-connectors play a substantial role, and weak ties help in further diffuse the message, on the contrary monetary incentive are not important.
\end{abstract}

${ }^{*}$ The Authors own full responsibility of the contents of the research and collaborated to all parts of the article.

${ }^{* *}$ ESCP Europe, Turin Campus. E-mail: fpucciarelli@escpeurope.eu.

${ }^{* * *}$ University of Turin, Department of Management. E-mail: chiara.giachino@unito.it.

**** University of Turin, Department of Management.

***** Innovation Consulant, Google Cloud.

Mercati \& Competitività (ISSN 1826-7386, eISSN 1972-4861), 2019, 1

Copyright $\odot$ FrancoAngeli

This work is released under Creative Commons Attribution - Non-Commercial

- NoDerivatives License. For terms and conditions of usage

please see: http://creativecommons.org 
Keyword: social media, social network sites, word-of-mouth, social word-of-mouth, start-up, digital marketing, target search process.

First submission: 12/02/2018, accepted: 11/02/2019

\section{Introduction}

The rapid rise of Web 2.0 and the almost universal adoption of social media are pinpointed as new marketing opportunities for companies from many parts. If originally, social networks were designed for conversational and sharing purposes, by adding functionalities, they became the 21 's century dominant media: democratizing communication and enabling individuals to inundate the web with their opinions about everything (Holt, 2016).

What is new here is the unprecedented capability of Web 2.0 of spreading around new (and established) ideas, throughout consumers real-time information exchanges, and with a much greater audience (Kaplan \& Haenlein, 2010). The more the post' likes, shares, and comments, the bigger the snowball effect, passing the message one to the other, allowing to reach people who don't follow (or even know) the original sender or brand (Broncanello $\&$ Tremiterra, 2015). If this snowball effect is true for any publisher, individual or company, could be argued that some company could be facilitated in leveraging the potential of these viral campaign because of their digital skills. For example, start-ups are generally very familiar with the online and social media, since they are digital native. Plus, it can also safely argued that social media characteristics well address start-ups continuous quest for creative solutions to overcome budget constraints (Gandolfo \& Lupi, 2014): social media allows to potentially reach a huge amount of people quickly, easily, with a low budget effort (Graham, 2012) and, even outweighed both personal preference and marketing communications (Kotler, Kartawajaya \& Setiawan, 2016). Furthermore, start-ups heavily rely on Word-Of-Mouth (WOM) to get to know and get known by the right audience interested in supporting their business: starting with founder talking about its idea to everyone to test it and gather feedbacks and other vital resources, talking to investors explaining why the start-up has potential, and so on and so further in the attempt of raising the highest level of interest on the entire community.

In conclusion, considering that nowadays Social Network Sites are the main and most natural venues for online conversations among customers (Pucciarelli, 2017), and that WOM represents an important marketing tool for a lot companies, the paper aims at demonstrating the potential impact of

Copyright $(\odot$ FrancoAngeli

This work is released under Creative Commons Attribution - Non-Commercial - NoDerivatives License. For terms and conditions of usage please see: http://creativecommons.org 
social Word-of-Mouth (sWOM) using an online community made by students of the ESCP Europe business school, among which a lot of start uppers are present. In particular, the research estimated the length of the path that connect two random people in the identified online community. Authors selected three target people to reach, three start uppers, and launched the campaign through the community to reach them. The start-up environment represent an ideal contest in which to test the sWOM for the specific characteristics it possess and its propensity toward the online world. The empirical adaptation of Milgram's Small World Experiment approach to the determined online community enable authors in demonstrating the potential of interconnected communities in enhancing sWOM that can be used by startups to boost their awareness among people and to reach the potential target identified investing a low budget.

\section{Theoretical foundation}

\subsection{The Small World experiment}

The study of factors influencing probability of communication to reach certain individuals find its roots in the $60 \mathrm{~s}$, when mathematical graph theorists studied the probabilities to reach with communications certain individuals through a social network. The variables investigated at that time were the structure of a social network and the dynamics of diffusion of a message - or of a disease - varying the distances from the source and the type of relationships (Rapoport \& Horvath, 1961).

In this context, Stanley Milgram, an U.S. psychologist, approached social networks studying the mobilization of existing ties - instead of the transition probabilities in a static network - to test "The Small World" phenomenon. Milgram aim was to determine the probability that any two randomly chosen individuals will know each other, trying to uncover the connections lurked in the networks of friends and acquaintances within the American context (Milgram, 1967; Travers and Milgram, 1969). The author ended the study with the "six degrees of separation", the average path length for connecting people in the United States.

Milgram's research about interpersonal relations in social network has been the basis for a lot of following sociological models, such as Coleman's association of social capital with "closed" networks, Granovetter's theory of weak ties, Burt's structural holes, and Domhoff's studies of social class (Domhoff, 1967; Granovetter, 1973; Coleman, 1990; Burt, 2009).

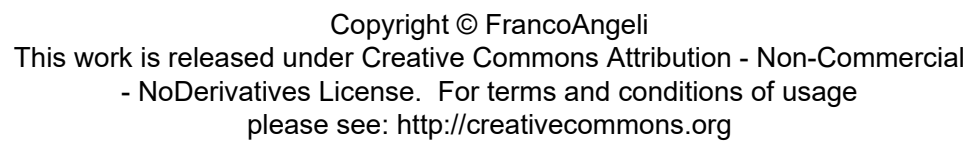


Nowadays Milgram's research is important to understand the structure of certain social networks and to define their potential in term of reach people and efficacy of information diffusion. And with the exception of research on job matching through social contact targeted search process research is scares (Schnettler, 2009), and call for investigation in a wider range of actual network arise from more recent literature (Granovetter, 2003).

This is why the application of "Small World" to the start-up environment could be particularly interesting (and original to certain extent), as the ability to be connected with selected people, such as potential investors, early adopters, etc., is crucial for start-ups in their growing phase. In fact, if it is considered the growth stage of a start-up, it is easy to understand the relevance of this core phase (i.e. it determines the future success and size of the company), and consequently it is fundamental to have the wider diffusion possible among potential customers willing to buy the product or service (Graham, 2012). This is the phase during which people are influenced mostly by the so called internal influence: the WOM communication (Mahajan, Muller \& Bass, 1990).

Word-of-Mouth is the essence of viral marketing, which is defined by Kaplan and Haenlein (2011, on page 255) as "the electronic Word-Of-Mouth (eWOM - named in the rest of the paper also sWOM) whereby some forms of marketing message related to a company, brand, or product is transmitted in an exponentially growing way, often through the use of social media". Exponential growth of message diffusion characterized by both speed and volume of people reached with the viral campaign within the online social network.

\subsection{Social Networks and degrees of separation}

Paul Graham (2012) underline as the only important thing for a start-up is to grow fast and that growth is the leading objective. A start-up is most of the time founded on a new and overlooked idea created on a new environment and emerging opportunity. The rising of the Internet and social media have been a huge wave of opportunities for many start-up founders in which they found the possibility to leverage the scale of an interconnected social network of people.

The measurement of intrinsic degrees of separation has been investigated in virtual communities by a number of studies (Dodds, Muhamad \& Watts, 2003; Leskovec \& Horvitz, 2008; Backstrom et al., 2012).

Doods, Muhamad \& Watts (2003) social-search experiment in which more than 60,000 e-mails users attempted to reach one of the 18 targets in

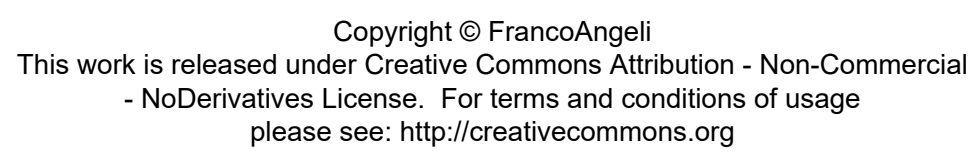


13 countries confirm the six degrees of separation - resulting in a median of 5 to 7 steps - and pinpointed as success factor individual incentives.

In 2008, Leskovec and Horvitz (2008) analyze the existing chain length among Microsoft Messenger's users, basing their study on the communications between two people not taking into account friendship links. They considered a communication graph with 180 million nodes and 1.3 billion edges extracted from a snapshot of the Microsoft Messenger network, and found an average distance of 6.6 intermediaries between two randomly chosen individuals (i.e., 5.6 intermediaries; again, rounding up, six degrees of separation).

In a more recent experiment on Facebook users Backstrom and colleagues (2012) shown that thanks to the degree of interconnectivity brought by the web 2.0, the number of intermediaries has incredibly reduced and the distance between two people, shifted from six degrees to four degrees of separation (average distance observed was 4.74 , corresponding to 3.74 intermediaries).

Obviously, from a company or a start-up's perspective social interactions and the relationships pillars must be considered in order to achieve success in reaching people in a faster way. In fact, a smart use of social media from a company or a start-up should leverage the four pillars defining social interactions and relationships, described by previous literature on eWOM and social networks: strength of ties (Granovetter, 1973), homophily (Gilly et al., 1998), trust (Nisbet, 2006), and interpersonal influence (Bearden, Netemeye \& Teel, 1989).

The American sociologist Mark Granovetter, in his masterpiece "The Strength of Weak Ties" (1973) demonstrates that people outside our closed group of friends - so called weak ties - are the one that allow an exponential diffusion of a message over social networks thanks to their bridging characteristics. Weak ties are crucial to enlarge people background knowledge, to have a wider range of information exchange, augmenting social search success (Doods, Muhamad \& Watts, 2003).

Homophily - namely similarity in a social group of people - instead could have a blocking effect on eWOM as similarities do not lead to opinion seeking or passing. However, individuals that present a high similarity are more likely to interact and to create clusters of strong ties, more narrowly targeted segments that could positively impact the acquaintanceship and the influence of eWOM on attitudes and decision-making process (Dobele, Toleman \& Beverland, 2005; Watts, Dodds \& Newman, 2002).

Trust in social contacts - the third pillar of social interaction and relationship - affects one of the most relevant piece of online communication: the

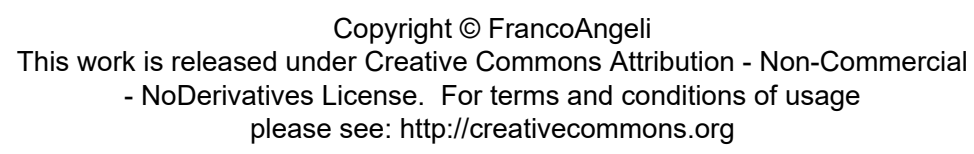


information sharing and customers' comments (Dallarocas, 2003). References and comments build consumers trust and increase the likelihood of passing along the WOM.

Finally, interpersonal influence is considered as a social construct that affect consumer purchase behaviours and decisions (Chu \& Kim, 2011); however, it can be argued that this aspect vary a lot across person, so it has to be considered the level of influenceability of single person (Bearden, Netemeye \& Teel, 1989) and it depends sensitively on individual incentives (Dodds, Muhamad \& Watts, 2003)

Role of incentives based campaign should thus be verified as potential eWOM enabler. A viral marketing campaign should be stimulated sometimes to maximize its effects and outcomes, as it happens for advertisement (Giachino et al., 2017). "The most important goal of every social network campaign is to maximize the spread of information across the network while keeping the campaign budget on a minimum level" (Michalski, Jankowski \& Kazienko, 2012, on page 1).

A set or theoretical models have been studied to create successful incentive plans (Takata et al., 2010) or rewarding package for social networks users and relative scenarios (Dayama, Karnik, \& Narahari, 2012). Researches in psychology showed that external incentives, gifts or money, are not the best way to motivate people (Fehr and Falk, 2002). Most of the time, users are self-motivated, intrinsic motivation, by the reward they get by helping other people (Levine, 1998) or gaining social approval (Dufwenberg \& Lundholm, 2001).

From the results carried out of a research made by Michalski and colleagues (2012) emerged that incentivized campaigns for activity are not necessarily better than those without incentives. Economic incentives may have an inverse result or not stimulate as much as the influencer would like to (Fehr \& Falk, 2002). Incentivized campaigns have been found to be more similar to mass media campaigns where messages are broadcasted to groups of untargeted users.

With incentives, it could be questionable whether the campaign will be properly targeted because the intrinsic interest of individuals involved in the campaign could be biased by the interest in the incentive rather than the real product or service promoted (Stewart, Ewing, \& Mather, 2009). Incentivized campaigns delivered to customers that are interested solely in incentives, and are outside of the target market, might be ineffective and counterproductive (Bampo et al., 2008). 


\section{Methodology}

A Small Word network is present where the number of intermediaries required to connect two randomly chosen nodes grows proportionally to the logarithm of the number of nodes in the network (Watts \& Strogatz, 1998). For the purpose of this paper ESCP Europe social community has been chosen as example of a determined and closed social network of start-ups and people with a focal centre - the ESCP Europe Business School itself -, to test the processes of information diffusion. The online community of ESCP Europe students and ex-alumni is a small world in which are present at the same time students, start-uppers and managers, and each one of them is living all around Europe. For this reason is a good place in which to test the effect of an online campaign and its effectiveness; moreover, the fact that at the same time are involved in the experiment people with different work positions, needs and interests can replicate the real situation: it is necessary to catch the attention of people to reach a target objective. The community chosen for the experiment has all the four pillars able to enhance social communications: strength of ties (Granovetter, 1973), homophily (Gilly et al., 1998), trust (Nisbet, 2006), and interpersonal influence (Bearden, Netemeye \& Teel, 1989). Weak ties because inside the community there are strong ties between students of the same class for example, but also weak ties with students of other campuses or years; homophily because the group membership students sharing years sitting together in the classes of the same business school presents more similarities; trust in social contacts because begin part of the same communities, sharing the same experience can enhance the level of trust between individual that do not know each other; and, finally, interpersonal influence although it depends from individual can be present in the community analysed for the reasons previously mentioned.

The setting of our experiment based on ESCP Europe's online network has the aim to measure the average path length that separate the selected target people - three former ESCP Europe's students now start-up's founders and random ESCP Europe's current students and/or alumni invited (via email) to participate to the experiment, both with or without incentives.

The study tries to replicate Milgram's (1967) Small World experiment through a re-adaptation, using e-mails instead of normal letters and testing the Small World phenomena in a close network, with the incentive variable in differentiating the two chains used in the experiment. The degrees of separation existing in a defined social network would prove its structure, interconnectivity and its potential in information propagation in terms of length, speed and precision, and the 5.2 intermediaries calculated by Milgram are expected to decrease because of web 2.0, in the form of e-mails (instead of the physical letters used

Copyright $(\odot$ FrancoAngeli This work is released under Creative Commons Attribution - Non-Commercial - NoDerivatives License. For terms and conditions of usage please see: http://creativecommons.org 
by Milgram). At the contrary the role of incentives is expected to not play a crucial role in the acquaintance of chains formation and information diffusion, as proven by previous studies (see Michalski, Jankowski \& Kazienko, 2012).

\subsection{Design and structure of the experiment}

In the study authors decided to adopt the electronic mails (e-mail), instead of traditional paper mails used by Milgram (1967). In this case, the speed of communication affects incredibly the period of time in which the message "infection" spreads and potentially allows an exponential growth in propagation on a social network.

Authors decided to use MailChimp e-mail as tool for the experiment, to design, diffuse and track the email experiment results among participants, instead of largely populated (such as Facebook, LinkedIn and Twitter) because of traceability of data propagation and chain formation. Which would not have been possible in those renowned social networks sites.

Second, ESCP Europe's mailing lists of current students and Alumni of the last three years was used, including thus in the experiment an age cohort of people that because of their age are considered as millennials. Younger generations (such as millennials) are particularly interesting because of their behavior and attitude towards new topics and concept of living life (Bonadonna, Giachino \& Truant, 2017).

Then, three target people were selected following some steps: first of all, target people have to be an ESCP Europe's alumnus and work in their own start-up; secondly, the start-up has less than five years and, finally, it was used a random sampling technique to identify a population matching these criteria. Each step followed Milgram's experiment guidelines in terms or arbitrary selection of target person. Ten current start-up founders have been selected from the five countries where ESCP Europe has its campuses venues - Italy, Germany, France, Spain and United Kingdom - to enhance the potential leverage in place in the network and hub of relationships created by the local ESCP Europe's campus in the resident country.

The final three candidates have been selected on characteristics previously stated and the similarity with the experimenter's academic path in the ESCP Europe to increase the likelihood to have longer acquaintance chains in the experiment.

The starting population was of 1,566 alumni (included in the mailing list), and each one of them has been contacted with an unsolicited email to take part in the experiment and to become the first link in a chain of acquaintances directed at the target person. 
Table 1 - Number of email per campaign

\begin{tabular}{lcc}
\hline Target & With incentive & Without Incentive \\
\hline Target 1 & 261 & 261 \\
Target 2 & 261 & 261 \\
Target 3 & 261 & 261 \\
\hline
\end{tabular}

Source: author's elaboration

In contrast with Milgram's experiments (Milgram 1967; Travers and Milgram 1969) a reward, consisting in 100 euros to spend on Amazon in form of coupon, was offered as an incentive for completion of chains to half of the participants in the study: the starting population and following intermediaries eventually engaged from the starting population.

The incentive system was applied to half of the initial population to test its impact in the acquaintance chains formation, as Monetary incentives have been proven to reduce dropout from survey completion (Reips et al., 1999), and eWOM diffusion process of a message. The sample that received the email with the incentive has been randomly chosen.

The e-mail was structured in different sections, and started with a short incipit to explain the project and asking for participation. Two version of the introduction was created, namely one for participants with incentives, and one for the ones without incentives. Every e-mail was addressing the participant with his/her first name, there was an explanation about the experiment and, for the selected people, there was the incentive specification. Then the rules of the game were explained and a text box with a photo of the target people and the link to the public profile in LinkedIn was inserted. The visual recognition of a person it is more effective than a test only description of an individual, pictures are better remembered than words on recognition tests (Ally \& Budson, 2007).

If the participant knew personally the Target person was requested to fill in the sender form (present in the email) and send it to the target person. If the participant did not know the Target person personally was requested to specific form and forward it to a friends or acquaintance that was more likely to know the Target person. More specifically, the sender form was structured with two buttons: "I know him" and "I don't know him". Once a participant clicked one of the two buttons, they were immediately redirected to a specific Google Form they had to fill with few basic information that allow authors to track the different steps toward the Target person.

Finally, there was a section about the description of the six degrees theory and a thank you GIF as a present for participants.

MailChimp allowed the creation of professional and well-designed e-mail thanks to an easy drag and drop design editor that allowed us to embed in the body of the e-mail interactive buttons and creative layouts.

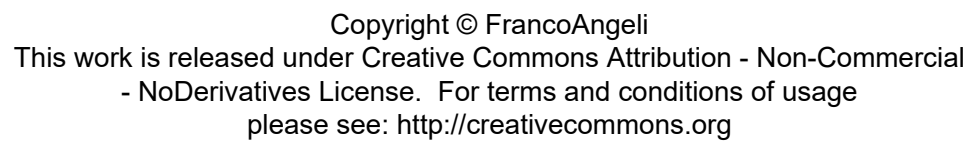


Six different campaigns have been created for the three distinct target people, divided three with incentive and three without incentive.

\section{Results}

The data gathered in the empirical experiment allowed us to define a degree of interconnectivity in the ESCP Europe network used as a proxy for the social distance existing in a closed community social network in order to test and verify the effectiveness to reach a specific target.

The key success factor in a Small World experiment is the active participation of the starting population that directly affects the first step of e-mails diffusion. In our experiment, the participation rate is defined as the percentage of respondents who actively opened and clicked though in the e-mail (see table 2).

Table 2 - Number of email sent out and participation rate

\begin{tabular}{lccc}
\hline Target person/campaign & No. Email sent out & $\begin{array}{c}\text { No. Email forwarded } \\
\text { (chain started) }\end{array}$ & Paticipation Rate \\
\hline Target 1 - Incentive & 261 & 24 & 14,6 \\
Target 1 - Non Incentive & 261 & 14 & 7,4 \\
Target 2 - Incentive & 261 & 33 & 15,7 \\
Target 2 - Non Incentive & 261 & 17 & 7,9 \\
Target 3 - Incentive & 261 & 15 & 9,4 \\
Target 3 - Non Incentive & 261 & 31 & 15,2 \\
\hline \multicolumn{1}{c}{ Total } & $\mathbf{1 5 6 6}$ & $\mathbf{1 3 4}$ & $\mathbf{1 1 , 7}$ \\
\hline
\end{tabular}

Source: authors' elaboration

Out of the 1,566 e-mails sent out to the list of potential participants, starting population, only 134 participants actively participated in the experiment and sent out the e-mails to their friends or acquaintances. Forwarding their e-mails 134 acquaintance chains have been created.

If it is considered the total number of e-mails sent out in the experiment $(1,566)$, the participation rate is $8.6 \%$, but considering that just 1,144 are the opened e-mails by participants, the overall participation rate is $11.7 \%$ and its value is more or less aligned with the past experiments on the small world phenomenon.

Beside the participation rate, we considered also the success rate indicator (see table 3). The success rate is defined here as the percentage of the number of chains that successfully reached the target. 
Table 3 - Target success rate

\begin{tabular}{lccc}
\hline Target person/campaign & $\begin{array}{c}\text { No. Email } \\
\text { forwarded (chain } \\
\text { started) }\end{array}$ & $\begin{array}{c}\text { Campaign } \\
\text { Success Rate }\end{array}$ & $\begin{array}{c}\text { Target Person } \\
\text { Success Rate }\end{array}$ \\
\hline Target 1 - Incentive & 24 & 37,5 & 39,5 \\
Target 1 - Non Incentive & 14 & 42,9 & \multirow{2}{*}{14} \\
Target 2 - Incentive & 33 & 9,1 & 21,8 \\
Target 2 - Non Incentive & 17 & 23,5 & \\
Target 3 - Incentive & 15 & 46,7 & \\
Target 3 - Non Incentive & 31 & 9,7 & \\
\hline \multicolumn{1}{c}{ Total } & $\mathbf{1 3 4}$ & $\mathbf{2 3 , 9}$ & \\
\hline
\end{tabular}

Source: authors' elaboration

Out of the 134 e-mails forwarded the total success rate was measured as $23,9 \%$; the result it is aligned with previous studies in literature, as the one obtained by Travers and Milgram (1969) was about 29.5\%.

The best result has been recorded by Target 1 with a success rate of $39.5 \%, 15$ out of 38 chains succeeded in reaching the target: 9 for the incentivized campaign $(37.5 \%)$ and 6 in the standard campaigns (42.9\%). A similar result can be detected in the analysis of Target 3 with a success rate of $21.7 \%, 10$ chains out of 46 found the target person: 7 for the incentivized campaign (46.7\%) and 3 in the standard campaigns (9.7\%). Target 2 with a success rate of $14.0 \%$, showed the worst track record in the experiment with 7 chains completed out of 50: 3 for the incentivized campaign $(9.1 \%)$ and 4 in the standard campaigns (23.5\%).

Furthermore, as shown in table 3 results obtained by the research doesn't show clearly the positive effect of incentive on message propagation: although if the number of chains with monetary incentive that reached the target person are a little bit superior with respect to the ones without monetary incentive ( $26 \%$ versus $21 \%$ ), it is not possible to affirm that incentives cover a fundamental role in reaching the target. Some limitations lie in the message itself that have been delivered to the participants in terms of involvement and engagement. Participants did not have a clear self-interest and inclination with the "product", the message, and this could have affected the experiment results with a low participation rate.

Another interesting results is about the chain development and the data of dropout, in fact, chains terminate either through completion or dropout: each dropout results in an incomplete chain (Milgram, 1967; Travers and Milgram, 1977). Table 4 shows the chain development analysis, where the dropout rate has been $91.44 \%$. Then from $1^{\text {st }}$ remover on engagement rate were much higher. 
Table 4 - Chain development analysis

\begin{tabular}{ccccc}
\hline \multicolumn{5}{c}{ All chains } \\
\hline Remove & $\begin{array}{l}\text { Chains Reaching } \\
\text { each remove }\end{array}$ & $\begin{array}{l}\text { Completion at } \\
\text { this remove }\end{array}$ & $\begin{array}{l}\text { Dropout at this } \\
\text { remove }\end{array}$ & $\begin{array}{c}\text { Per cent } \\
\text { Dropout }\end{array}$ \\
\hline 0 & 1566 & 0 & 1432 & $91,4 \%$ \\
1 & 134 & 9 & 74 & $5,3 \%$ \\
2 & 51 & 19 & 24 & $2,8 \%$ \\
3 & 8 & 3 & 4 & $0,5 \%$ \\
4 & 1 & 1 & 0 & $0,1 \%$ \\
\hline Total & & $\mathbf{3 2}$ & $\mathbf{1 5 3 4}$ & $\mathbf{1 0 0 , 0 \%}$ \\
\hline
\end{tabular}

Source: authors' elaboration

The reason of the high percentage of dropout at a first stage is probably link to the importance given to the email coming from a friend or acquaintances, that increases the engagement of individuals and move them directly from an awareness to an interest phase in their decision making process that could move even forward to a consideration and purchase phase -.

Finally, the last stage is about the measurement of the length of completed chains (see table 5). Small world networks are highly clustered networks in which the average path length remains relatively short (Uzzi, Amaral \& Reed-Tsochas, 2010).

Table 5 - Length of completed Chains

\begin{tabular}{cc}
\hline \multicolumn{2}{c}{ Length of completed chains } \\
\hline Number of intermediaries & Number of completed chains \\
\hline 0 & 0 \\
1 & 9 \\
2 & 19 \\
3 & 3 \\
4 & 1 \\
\hline Average & $\mathbf{1 , 9}$
\end{tabular}

Source: authors' elaboration

In the presented study the average path length is 1,9 intermediaries a much shorter result compared to Milgram's six degrees of separation. The resulted path is considerably short and effective due to the high interconnectivity of the ESCP Europe community network.

Aligned with Milgram's results about interconnectivity, "super-connectors" in the ESCP Europe community bridge clusters of strong ties allowing to weak ties to be formed and information to flow more fluently. "Super connectors" are those individuals that have a high number of connections, the 
essential nodes to have network's cohesion. The study carried out that about $15 \%$ of the people engaged in the experiment, among the started chains, have been involved in $30 \%$ of the following chains as key links (as shown in table 6).

Table 6 - Total number of participants in the study

\begin{tabular}{ccccc}
\hline \multicolumn{5}{c}{ Total Number of participants in the study } \\
\hline $\begin{array}{c}\text { Number of } \\
\text { intermediaries }\end{array}$ & Total chains & $\begin{array}{l}\text { Total } \\
\text { participants }\end{array}$ & $\begin{array}{l}\text { Recurrent } \\
\text { participants in } \\
\text { following chains }\end{array}$ & $\begin{array}{l}\text { \% of } \\
\text { participants }\end{array}$ \\
\hline 1 & 134 & 134 & 20 & $15 \%$ \\
2 & 51 & 102 & 16 & \\
3 & 8 & 24 & 4 & $33 \%$ \\
4 & 1 & 4 & 0 & \\
\hline Total & $\mathbf{1 9 4}$ & $\mathbf{2 6 4}$ & $\mathbf{2 0}$ & \\
\hline
\end{tabular}

Source: authors' elaboration

Meaning that eWOM has a remarkable impact when diffused among a closed social network, as the role of "super connectors" enhances the information propagation and boost products and services awareness or interest in individuals.

\section{Conclusions}

The new way of being entrepreneurs today is looking for cheap and effective marketing tools to implement effective growth strategy.

This study adopts an original approach on the topic of viral marketing as strategy to understand if viral marketing can be used by start-ups in order to grow faster and reaching a higher diffusion than the common tools used, and provides an understanding of the impact of the social Word-of-Mouth dynamics in closed community networks.

Authors decided to replicate Milgram's experiment (1967) of "six degrees of separation" between people, in a closed community such as the one of a business school. The experiment was replicated using e-mails and two different way of proposing the experiment: with and without economic incentive.

Our analysis confirmed that the path length existing between two randomly chosen people in a defined social network is incredibly short: findings show that the proximity of people in a well-interconnected social network

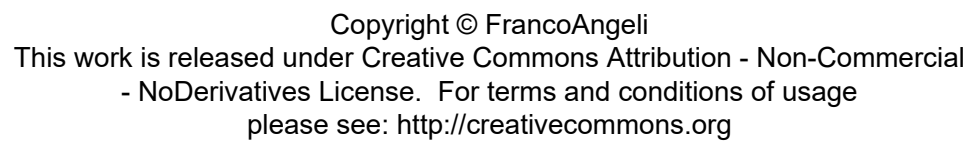


assure more effective and fastest ways to communicate and reach a specific target, shortening the original 6 degrees of separation today are 1.9 degrees of separation. This means that on average there are two people between a person and a specific target. It suggests that short paths exist between two randomly chosen individuals in close networks, implying that anyone -early stage start-ups included- can easily find this short path to potentially reach any target in the network. The proximity of people in a well-interconnected social network allows a more effective and faster diffusion of information among the community. Therefore, the magnitude of the information impact is more relevant and powerful in increasing awareness and influencing individuals' choices.

Whilst uncertain effectiveness of gifts and other sort of incentives seems not to influence message propagation in reaching the target.

The doubts that incentives could be positively correlated with an increase in effectiveness for a viral campaign are still present and to be proved for each situation (and it could constitute a relevant field of further investigation). The Word-of-Mouth has a remarkable impact when diffused with efficacy among a closed social network: the role of "connectors" enhances the information propagation and boost products and services awareness or interest in individuals.

The high interconnectivity in a social network could induce different types of interactions, personal and business related with the start-up or company. More frequent individuals' interactions among a defined network, as the start-up network, would produce business opportunities for start-ups, if sought, and impact the growth and future developments.

The manuscript thus contributes to the on-going debate on social media marketing application illustrating how a well-interconnected network can positively impact and accelerate the growth of a start-up, in terms of both customer base and opportunity seeking.

The application of the social network's theory to a closed and defined social network sheds light on the importance of building a well interconnected network for start-ups that want to grow with low budgets in competitive environments. This study pioneered an original approach on the topic of viral marketing as strategy to boost start-ups growth, and it provides an understanding of the impact of the Word-of-Mouth dynamics in closed community networks and how this could impact information diffusion to speed up start-up growth. Consequently, the findings of this research may serve start-ups and established companies in guiding their efforts to design their marketing strategies and public relations to establish key connections to boost growth and innovation. 
Resuming the above results, two particular recommendations for start uppers willing to unleash viral marketing potential to reach a defined target stand out.

First, find your "super-connectors": those small number of people that are better connected in the defined network and that have substantial influence on the opinions and decisions of the majority. Super connector play an important bridging role as influencers and information diffusion boosters.

Second, be trustworthy and make new friends: the raising indifference in consumers toward branded sponsored communication could be overcome using trustworthy sources and meaningful contents. Viral marketing could be an effective tool and solution to overcome people's indifference and reluctance in advertising. In the "small" world of the Internet, where everyone is connected, we could exploit the interpersonal links existing between individuals for the purpose of marketing, being social has never been more useful. In conclusion, from a managerial point of view, this research demonstrates how fast and effective can be the online world to reach objective and target market. The fact is that people knows the opportunities given by viral marketing and social media activities but start-ups, companies and their managers often think that is to expansive to manage social media with the objective to rise the visibility. The lesson learned is that choosing the right small world is possible to reach a specific target in few steps. For start-ups this is fundamental to reach potential investors or gain visibility as soon as possible. The online campaign can be an important tool to develop the business in its early stage.

Limitations of this study lead to future research opportunities. As Milgram and Travers (1969) elaborated in their study an important limiting factor is lurked behind the participants, and not in the experiment itself, in terms of engagements through the experiment. Limitation that was present in the proposed experiment in the message itself that have been delivered to the participants. As participants did not have a clear self-interest and inclination with the "product" this could have affected participants involvement and engagement, and thus the experiment results. Moreover, even if significant from a statistical perspective - the 134 participants for the experiment exceed the needed 30 participants per experimental group - a larger sample size for the experiment would have been desirable.

In future, an important regard should be taken into consideration to analyse the decision making process of individuals in social networks and how their behaviour could impact the growth of start-ups. How people interact with each other and on which degree of knowledge they have a clear impact on start-ups boosting connection and bringing a decisive value. 
Furthermore the impact on sales and brand awareness in a closed community network that presents Small World characteristics need further investigation to study if Word-of-Mouth could be an effective growth strategy for start-ups compared to established companies, basing the research on the following step after the Word-of-Mouth propagation, in the purchasing moment. The comparison between economic results of viral campaigns on startups and established companies could provide the necessary information to benchmark the impact of the Word-of-Mouth as growth strategy.

\section{References}

Ally B. A., \& Budson A. E. (2007). The worth of pictures: Using high density eventrelated potentials to understand the memorial power of pictures and the dynamics of recognition memory. NeuroImage, 35(1): 378-395, doi: 10.1016/j.neuroimage.2006.11.023.

Backstrom L., Boldi P., Rosa M., Ugander J., \& Vigna S. (2012, June). Four degrees of separation. In: Proceedings of the 4th Annual ACM Web Science Conference (pp. 33-42). ACM.

Bampo M., Ewing M. T., Mather D. R., Stewart D., \& Wallace M. (2008). The effects of the social structure of digital networks on viral marketing performance. Information systems research, 19(3): 273-290. DOI: 10.1287/isre.1070.0152.

Bearden W. O., Netemeyer R. G., \& Teel J. E. (1989). Measurement of consumer susceptibility to interpersonal influence. Journal of consumer research, 15(4): 473-481. DOI: $10.1086 / 209186$.

Bonadonna A., Giachino C., \& Truant E. (2017). Sustainability and Mountain Tourism: The Millennial's Perspective. Sustainability, 9(7): 12-19. DOI: 10.3390/ su9071219.

Broncanello I., \& Tremiterra M. (2015). Il ruolo delle risorse e delle competenze organizzative dell'impresa nell'utilizzo e implementazione del web 2.0: il caso delle imprese della strada dell'olio in Umbria. Mercati e competitività, 4: 105131. DOI: 10.3280/MC2015-004006.

Burt R. S. (2009). Structural holes: The social structure of competition. Harvard University Press.

Chu S.-C., \& Kim Y. (2011). Determinants of consumer engagement in electronic word-of-mouth (eWOM) in social networking sites. International journal of Advertising, 30(1): 47-75. DOI: 10.2501/IJA-30-1-047-075.

Coleman J. (1990). Foundations of Social Theory. Cambridge, Mass.: Belknap Press of Harvard University Press.

Dallarocas, C. (2003). The digitization of word-of-mouth: promise and challenge of online feedback mechanisms. Management Science, 49(10): 1407-1424.

Dayama P., Karnik A., \& Narahari Y. (2012). Optimal mix of incentive strategies for product marketing on social networks. arXiv preprint arXiv:1203.0135.

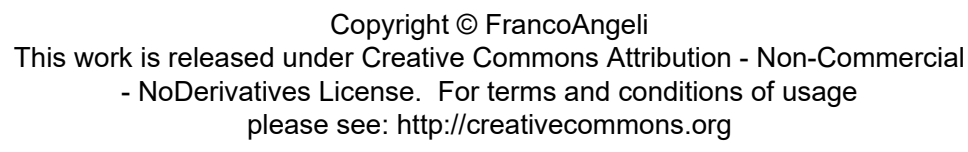


Dobele A., Toleman D., \& Beverland M. (2005). Controlled infection! Spreading the brand message through viral marketing. Business Horizons, 48(2): 143-149. DOI: 10.1016/j.bushor.2004.10.011.

Dodds P. S., Muhamad R., \& Watts D. J. (2003). An experimental study of search in global social networks. Science, 301(5634): 827-829. DOI: 10.1126/science. 1081058 .

Domhoff G. W. (1967). Who Rules America? . Englewood Cliffs, N.J.: Prentice Hall.

Dufwenberg M., \& Lundholm M. (2001). Social norms and moral hazard. The Economic Journal, 111(473): 506-525. DOI: 10.1111/1468-0297.00648.

Fehr E., \& Falk A. (2002). Psychological foundations of incentives. European economic review, 46(4-5): 687-724. DOI: 10.1016/S0014-2921(01)00208-2.

Gandolfo A., \& Lupi L. (2014). Social network branding: la politica di marca nell'era delle reti sociali digitali. Mercati e competitività. DOI: 10.3280/ MC2014-002008.

Giachino C., Stupino M., Petrarulo G., \& Bertoldi B. (2017). Fear appeals in social marketing: The case of anti-speeding video advertisement "Mistakes". Journal of Customer Behaviour, 16(1). DOI: 10.1362/147539217X14909732699480.

Gilly M. C., Graham J. L., Wolfinbarger M. F., \& Yale L. J. (1998). A dyadic study of interpersonal information search. Journal of the Academy of Marketing Science, 26(2): 83-100. DOI: 10.1177/0092070398262001.

Graham P. (2012). Want to start a start up? Get funded by Y Combinator. -- Available at http://www.paulgraham.com/growth.html.

Granovetter M. (1973). The strength of weak ties, American Journal of Sociology, 78: $1360-1380$.

Granovetter M. (2003). Ignorance, knowledge, and outcomes in a small world. Science, 301(5634): 773-774. -- Available at http://smg.media.mit.edu/library/SmallWorld2003/Granovetter.perspective.pdfgg.

Holt D. (2016). How Digital Has Changed Branding. Harvard Business Review, 94(5): 18.

Kaplan A. M., \& Haenlein M. (2010). Users of the world, unite! The challenges and opportunities of Social Media. Business horizons, 53(1): 59-68. DOI: 10.1016/ j.bushor.2009.09.003.

Kaplan A. M., \& Haenlein M. (2011). Two hearts in three-quarter time: How to waltz the social media/viral marketing dance. Business Horizons, 54(3): 253263. DOI: 10.1016/j.bushor.2011.01.006.

Kotler P., Kartajaya H., \& Setiawan I. (2016). Marketing 4.0: Moving from traditional to digital. John Wiley \& Sons.

Leskovec J., \& Horvitz E. (2008, April). Planetary-scale views on a large instantmessaging network. In: Proceedings of the 17th international conference on World Wide Web (pp. 915-924). ACM.

Levine D. K. (1998). Modeling altruism and spitefulness in experiments. Review of economic dynamics, 1(3): 593-622. DOI: 10.1006/redy.1998.0023.

Mahajan V., Muller E., \& Bass F. M. (1990). New product diffusion models in marketing: A review and directions for research. In: Diffusion of technologies and social behavior (pp. 125-177). Springer: Berlin, Heidelberg.

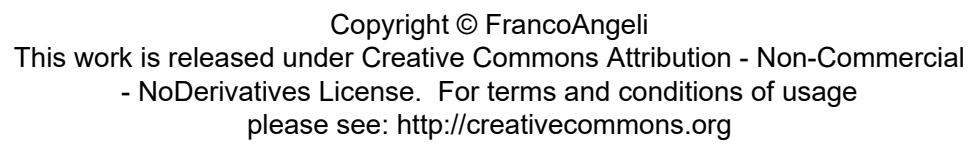


Michalski R., Jankowski J., \& Kazienko P. (2012, November). Negative effects of incentivised viral campaigns for activity in social networks. In: Cloud and Green Computing (CGC), 2012 Second International Conference on (pp. 391-398). IEEE.

Milgram S. (1967), The Small World Problem. Psychology Today, 1(1): 61-67.

Nisbet E. C. (2005). The engagement model of opinion leadership: Testing validity within a European context. International Journal of Public Opinion Research, 18(1): 3-30. DOI: 10.1093/ijpor/edh100.

Pucciarelli F. (2017). Strategizing social media presence. In: Bikramjit R. and Subir B. (Eds.). Contemporary Issues in Social Media Marketing. New York: Routledge, pp. 217-226.

Rapoport A., \& Horvath W. J. (1961). A study of a large sociogram. Systems Research and Behavioral Science, 6(4): 279-291. DOI: 10.1002/bs.3830060402.

Reips U. D., Batinic B., Bandilla W., Bosnjak M., \& Graf L. (1999). Financial incentives personal information and drop-out rate in online studies. In: Current Internet ScienceTrends, Techniques, Results. Deutsche Gesellschaft für OnlineForschung.

Schnettler S. (2009). A structured overview of 50 years of small-world research. Social networks, 31(3): 165-178.

Stewart D. B., Ewing M. T., \& Mather D. R. (2009, November). A conceptual framework for viral marketing. In: Australian and New Zealand Marketing Academy (ANZMAC) 2009 Sustainable Management and Marketing Conference (Vol. 30).

Takata Y., Hashimoto R., Shinkuma R., Takahashi T., Yoshinaga N., Itaya S., ... \& Yamada K. (2010, July). Incentive Rewarding Method for Information Propagation in Social Networks. In: Applications and the Internet (SAINT), 2010 10th IEEE/IPSJ International Symposium on (pp. 173-176). IEEE.

Travers J., \& Milgram S. (1977). An experimental study of the small world problem. In: Social Networks (pp. 179-197).

Uzzi B., Amaral L. A., \& Reed-Tsochas F. (2007). Small-world networks and management science research: A review. European Management Review, 4(2): $77-$ 91.

Watts D. J., Dodds P. S., \& Newman M. E. (2002). Identity and search in social networks. Science, 296(5571): 1302-1305. DOI: 10.1126/science.1070120.

Watts D. J., \& Strogatz S. H. (1998). Collective dynamics of 'small world' networks. Nature, 393(6684). DOI: 10.1038/30918.

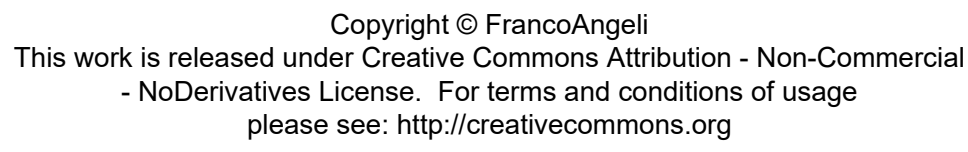

